\title{
Applications of Smartphone-Based Sensors in Agriculture: A Systematic Review of Research
}

\author{
Suporn Pongnumkul, Pimwadee Chaovalit, and Navaporn Surasvadi \\ National Electronics and Computer Technology Center (NECTEC), 112 Thailand Science Park, Phahonyothin Road, \\ Khlong Nueng, Khlong Luang, Pathum Thani 12120, Thailand
}

Correspondence should be addressed to Suporn Pongnumkul; suporn.pongnumkul@nectec.or.th

Received 7 April 2015; Revised 8 July 2015; Accepted 9 July 2015

Academic Editor: Pietro Siciliano

Copyright ( 2015 Suporn Pongnumkul et al. This is an open access article distributed under the Creative Commons Attribution License, which permits unrestricted use, distribution, and reproduction in any medium, provided the original work is properly cited.

\begin{abstract}
Smartphones have become a useful tool in agriculture because their mobility matches the nature of farming, the cost of the device is highly accessible, and their computing power allows a variety of practical applications to be created. Moreover, smartphones are nowadays equipped with various types of physical sensors which make them a promising tool to assist diverse farming tasks. This paper systematically reviews smartphone applications mentioned in research literature that utilize smartphone built-in sensors to provide agricultural solutions. The initial 1,500 articles identified through database search were screened based on exclusion criteria and then reviewed thoroughly in full text, resulting in 22 articles included in this review. The applications are categorized according to their agricultural functions. Those articles reviewed describe 12 farming applications, 6 farm management applications, 3 information system applications, and 4 extension service applications. GPS and cameras are the most popular sensors used in the reviewed papers. This shows an opportunity for future applications to utilize other sensors such as accelerometer to provide advanced agricultural solutions.
\end{abstract}

\section{Introduction}

Among the technologies invented in the past few decades, smartphones have gained large market shares among various user sectors due to their usefulness, ease-of-use, and affordability. The number of new smartphone users continues to grow. It is estimated that, by 2016, the number of users will be more than 2 billion people worldwide [1]. One factor that enhances the smartphones' ability to assist users to perform various tasks is the numerous built-in sensors (e.g., positioning sensors, motion sensors, and cameras microphones). Many industries have adopted smartphones to facilitate their work, such as health care $[2,3]$ and education $[4,5]$. This paper reviews the usage of smartphone sensors in an important sector, agriculture. Inexpensive smartphones equipped with various sensors are opening new opportunities for rural farmers who previously had limited access to upto-date agricultural information (e.g., market, weather, and crop disease news) and assistance from agricultural experts and government extension workers. Meanwhile, farmers in large-scale farms, who already adopt assistance from other information technologies, can now utilize smartphone-based sensors to increase productivity and facilitate various tasks throughout the farming cycle.

Ensuring food security has been a global concern throughout human history, and the global food crisis of 2007-2008 has emphasized the importance of increasing both quantity and quality of food production [6]. Agriculture, which is the upstream food producing sector, is, therefore, in need of new and modern methods to ensure the world's food security. Traditional agriculture was usually done within a family or a village and accumulative farming expertise and knowledge were passed down to their future generations. Human was the main observer of field conditions and the solution provider as problems arise. However, this traditional method is no longer suitable, because farming outputs depend largely on the natural surrounding conditions (e.g., weather and water) and global warming issues (causing frequent droughts and floods) and crop disease outbreaks are disruptive of farming productivity. Traditional within-group 
knowledge and human observations alone are not sufficient to battle the issues. Therefore, new methods for farming have been invented, for example, precision agriculture. One key idea of new practices in agriculture is the use of technology to measure or monitor field and crop conditions in order for farmers to make informed decisions in various parts of their farming process. Sensors for continuous and automatic measurements of different field values are one of the main success factors for precision agriculture [7].

Dedicated devices (e.g., a SPAD meter for leaf chlorophyll assessment [8], a Li-3100 for Leaf Area Index (LAI) measurement [9], and a spectroscopy for studying soil structure and components [10]) have been useful in agriculture but might be difficult to access for rural farmers who do not have access to the product providers or insufficient funds to purchase the devices. However, some of the tasks that the dedicated devices perform can be replicated on smartphones with builtin sensors. This provides an easy alternative for farmers who already own smartphones to easily download applications to use. This paper aims at reviewing how smartphone sensors have been used in agriculture in research literature and illustrates the range of applications that farmers can use for their work without having to purchase new hardware. Additionally, to the best of our knowledge, we are the first to review smartphone usage in agriculture with the focus on how sensors are used. This paper also highlights the open opportunities through which researchers and mobile developers can further utilize smartphones to provide better tools for agriculture.

In this survey, the authors categorize smartphone applications by their agricultural functions into four categories: farming, farm management, information systems, and extension services. Farming applications are those that assist in farming activities, such as disease detection and pesticide application rate calculation. Farm management applications facilitate users to manage overall farm resources and farming activities more efficiently and effectively in order to achieve better profit and farming productivity. Information system applications include systems that provide essential information for farmers, including farming knowledge, environmental context, and market information. Extension service applications provide assistance to the traditional agricultural extension where field workers visit farms. Extension service applications mostly provide channels for remote farmers to access expert consultation and provide tools for field workers to efficiently work while in the field.

A systematic review was conducted by a search for research papers on SCOPUS database, yielding 1,500 initial results. The search results were then screened by reviewing title, abstract, and keywords for exclusion criteria: smartphone applications only limited to voice, SMS, or accessing information via the Internet; primary domains of smartphone applications not in agriculture; smartphone applications only applied to non-plant-based agriculture; no smartphonebased sensor used in smartphone applications; full text articles not accessible; and articles written in languages other than English. This process resulted in 339 potentially relevant papers which were again reviewed more thoroughly in full text using the same exclusion criteria. The remaining
22 papers are included in this review and are categorized into the four categories discussed above. The papers (describing 12 farming applications, 6 farm management applications, 3 information system applications, and 4 extension services applications) are summarized with the focus of the smartphone sensor usages and their functions.

The remaining sections are as follows. Section 2 reviews the current technology of smartphone sensors. Then, Section 3 describes the method used to obtain the articles for this review. After that, the results are presented in Section 4 with subsections for each of the four categories. In Section 5, we discuss, in each subsection, respectively, the current usage of smartphone-based sensors in agriculture, their advantages with respect to traditional tools/methods, challenges for their usages in agriculture, and future research opportunities. Finally, Section 6 concludes the review.

\section{Smartphone Sensors and Their Use}

This section reviews common sensors of recent smartphones. Sensors are a device that measures a physical quantity and converts to a signal which can be read and used by other devices. An example of the traditional sensors is the thermometer which converts how hot or cold the environment is into a number, which is called the temperature. There are many kinds of sensors available nowadays, and many mainstream smartphones are equipped with various sensors, including accelerometers, GPS, light sensors, temperature sensors, gyroscope, and barometer.

The sensors embedded in smartphones can be classified into three categories: motion sensors, environmental sensors, and position sensors. The first category, motion sensors, provides acceleration force and rotational force measurements. Examples of motion sensors are accelerometers, gyroscopes, gravity sensors, and rotational vector sensors. The second category, environmental sensors, provides measurements of the surrounding environments. This ranges from ambient air temperature from a thermometer and pressure from a barometer to illumination from a photometer. The third category, position sensors, provides measurements of the device's physical position. Such sensors include magnetometers, GPS, and orientation sensors [11]. Table 1 describes the common smartphone sensors. For the purpose of this review, we exclude communication channels (e.g., WIFI, Bluetooth, 3G, and NFC) and display channels from the sensor list.

Recent increases in popularity of smartphones have called attention to researchers to explore the use of smartphone sensors in their work. Many sensors have been applied successfully in numerous areas. Global Positioning System (GPS) allows applications to obtain the current location of the device. Apart from direct uses of the location in applications (e.g., maps), GPS data have also been used to infer transportation modes [35]. Accelerometers, which measure the force of acceleration whether caused by the phone's movement or gravity in 3 axes, have been used as sensors in fall detection [3], activity recognition [36], driving event detection [37], and so forth. Built-in cameras (both front and rear cameras) of recent smartphones have improved greatly in terms of specifications over recent years. The camera 
TABLE 1: Common smartphone sensors [11, 12].

\begin{tabular}{|c|c|c|}
\hline Sensor & Description & Common uses \\
\hline Accelerometer & $\begin{array}{l}\text { Measures the acceleration force in } \mathrm{m} / \mathrm{s}^{2} \text { that is } \\
\text { applied to each of the three physical axes }(x, y \text {, and } \\
z \text { ) of a device (including gravity) }\end{array}$ & $\begin{array}{l}\text { Detects motion and senses the changes in } \\
\text { smartphones' orientation }\end{array}$ \\
\hline $\begin{array}{l}\text { Ambient temperature } \\
\text { sensor }\end{array}$ & $\begin{array}{l}\text { Measures the ambient room temperature in degrees } \\
\text { Celsius }\left({ }^{\circ} \mathrm{C}\right)\end{array}$ & Monitors air temperatures \\
\hline Gyroscope & $\begin{array}{l}\text { Measures a device's rate of rotation in } \mathrm{rad} / \mathrm{s} \text { around } \\
\text { each of the three physical axes }(x, y \text {, and } z)\end{array}$ & Detects rotation (spin, turn, etc.) \\
\hline Light sensor & Measures the ambient light level (illumination) in lx & Controls screen brightness \\
\hline Magnetometer & $\begin{array}{l}\text { Measures the ambient geomagnetic field for all three } \\
\text { physical axes }(x, y \text {, and } z) \text { in } \mu \mathrm{T}\end{array}$ & Creates a compass \\
\hline Barometer & Measures the ambient air pressure in $\mathrm{hPa}$ or mbar & Monitors air pressure changes \\
\hline Proximity sensor & $\begin{array}{l}\text { Measures the proximity of an object in } \mathrm{cm} \text { relative to } \\
\text { the view screen of a device }\end{array}$ & $\begin{array}{l}\text { Detects if the phone is held up to a } \\
\text { person's ear during a call }\end{array}$ \\
\hline Humidity sensor & $\begin{array}{l}\text { Measures the humidity of ambient environment in } \\
\text { percent }(\%)\end{array}$ & $\begin{array}{l}\text { Monitors dewpoint and absolute and } \\
\text { relative humidity }\end{array}$ \\
\hline Global Positioning System & $\begin{array}{l}\text { Measures the latitude and longitude of the current } \\
\text { location of the device }\end{array}$ & $\begin{array}{l}\text { Uses a user's location to show the nearby } \\
\text { information }\end{array}$ \\
\hline Image sensor (camera) & Records images and videos & Captures still picture or video \\
\hline Audio sensor (microphone) & Measures sound in air into an electrical signal & Records voices \\
\hline Fingerprint identity sensor & Reads a user's fingerprint & Identifies a user through touching \\
\hline Moisture sensor & $\begin{array}{l}\text { Identifies whether the device has been submerged in } \\
\text { water }\end{array}$ & $\begin{array}{l}\text { Detects if a device has internal water } \\
\text { damage }\end{array}$ \\
\hline
\end{tabular}

resolutions are now comparable with dedicated hand-held cameras. Therefore, smartphone applications can now be a single device, which takes as input the images or videos from built-in cameras, then uses its computation power to perform computer vision algorithms, and produces useful data from the input images. Examples of such applications include indoor positioning [38], heart rate extraction using video imaging [39], and pulse rate evaluation [40].

\section{Methods}

3.1. Data Sources of Systematic Review. We have adopted PRISMA [41], which is a basis framework for reporting systematic reviews, for our research. A literature search following the PRISMA guideline for articles from SCOPUS database was performed on February 2, 2015. Our goal was to search for articles featuring sensors in smartphones and their use in agriculture. Using the keyword "sensor(s)" in the search criteria yielded articles related to any types of sensors and not particularly smartphone-based sensors, and we were given a set of results with an overwhelming amount of articles to exclude. Therefore, we made a decision not to include the keyword "sensor(s)" as the inclusion introduced too many false positive articles to be later manually removed. Besides, a usage of various smartphone components as sensors in research can be quite subtle. For example, researchers often do not explicitly point out that the use of cameras to collect image data is "sensing" images using cameras on smartphones. Oftentimes they are explained as utilizing smartphones to perform certain agricultural tasks. Therefore, we decided to include "smartphone(s)" in our search criteria instead.

Since smartphones in the literature may be referred to by many terms such as "mobile phone(s)" or "mobile device(s)," we devised a set of words which can describe smartphones. The set of keywords are the following: "mobile application," "mobile app," "smartphone," "mobile device," and "mobile phone." With our goal of reviewing usage of smartphonebased sensors in agriculture, the previous set of keywords became search criteria in conjunction with the keyword "agriculture." Specifically, the phrase (("smartphone" OR "mobile device" OR "mobile phone" OR "mobile app" OR "mobile application") AND "agriculture") was entered into SCOPUS search engine. The search terms focused on the terms related to smartphones and agriculture. The search results were not limited by language or any time constraints. The result set from this search was then systematically reduced to only articles featuring sensors in smartphones and their use in agriculture by exclusion criteria.

3.2. Inclusion and Exclusion Criteria. In this systematic review, we are interested in articles that present the use as well as the development and evaluation of smartphonebased sensors in agriculture. Therefore, we searched the SCOPUS database using the keywords "agriculture" and many variations of "smartphone(s)." The search produced a list of articles with their use of onboard smartphone sensors, as intended.

The search also resulted in articles that feature smartphones but not their sensors. For instance, smartphones 
are used only as a communication means in agriculture work, when farmers use voice call or Short Message Service (SMS) to communicate crop prices, or when networkenabled smartphones are solely used as devices for accessing agricultural-related information. We decided to exclude those articles, as smartphones are not devised as sensors but only as communication devices. Also, we excluded articles that describe general systems which were not specifically designed for agricultural use. In addition, the scope of our review is plant farming; we therefore removed articles related only to animal farming. Furthermore, we review usage of smartphone-based sensors in agriculture in order to increase farmers' awareness of numerous applications that can be used in their farming cycle without having to purchase new dedicated devices. We, therefore, decided to exclude articles in which smartphones are used only as a remote terminal to monitor and control other external sensors, for example, external temperature and humidity sensors as in [42, 43]. In many cases, it is still not clear from a full text review if any built-in sensors are used in the applications. However, we decided to include certain articles in which although the authors did not clearly specify the sensors used, we can infer from the functionalities of the applications such as retrieving location data via GPS as in [27, 28, 31]. We also excluded articles written in languages other than English and those of which we could not access full text.

In summary, our exclusion criteria include (a) smartphone applications only limited to voice, SMS, or accessing information via the Internet; (b) primary domains of smartphone applications not in agriculture; (c) smartphone applications only applied to non-plant-based agriculture; (d) no smartphone-based sensor used in smartphone applications; (e) full text articles not accessible; and (f) articles written in languages other than English. The process of filtering out articles based on our exclusion criteria was performed manually.

3.3. Data Extraction. After irrelevant articles had been excluded based on the criteria above, we read the remaining 22 articles in full text to gather relevant information. We extracted information of what the smartphone applications utilizing onboard sensors are, which smartphone-based sensors are used, and how the sensors are used. We also accessed the smartphone application marketplaces to extract related data when applications are available on those markets.

3.4. Flow Diagram. The flow diagram presented in Figure 1 concludes the steps taken in our database search method and search result filtration. First, entering the search terms into SCOPUS search engine initially resulted in 1,500 articles. Second, the search result set was screened by title, abstract, and keywords following the exclusion criteria in Section 3.2, resulting in the exclusion of 1,161 articles. Third, the remaining 339 potentially relevant articles were examined thoroughly in full text using the same exclusion criteria. The final result list consisted of 22 eligible articles for comprehensive review of their contents with the focus of the smartphone sensor usages and their functions in agriculture. Those 22 articles, describing 25 smartphone-based sensor applications, are categorized based on their agricultural functions as follows: 9 articles describing 12 farming applications, 6 articles describing 6 farm management applications, 3 articles describing 3 information systems applications, and 4 articles describing 4 extension services applications.

\section{Results}

This section describes the smartphone applications from our survey. The applications were categorized into four categories: farming, farm management, information system, and extension services.

4.1. Farming Applications. Farming refers to a series of agricultural processes which involve various day-to-day activities on the field, for example, sowing, weeding, fertilizing, and making related agricultural decisions. Farming activities are focused on how to grow plants, kill weeds/pests, identify and correct plant diseases, apply fertilizers, and estimate growth/yield of crops. Recent advances in smartphone application development and an increasing availability of smartphones allow for some of these agricultural burdens to be lifted and guided. For example, farmers may calculate proper amounts of fertilizers for crop fields upon analyzing color of crop leaves with some help from smartphone applications. This section reviews smartphone applications under farming category and how they may aid farmers to achieve farming tasks.

Farmers have a number of responsibilities working in crop fields. A handful of tasks which are performed in the field, that is, seeding, weeding, fertilizing, and watering, may seemingly be repetitive, mundane, and labor-intensive. However, those tasks usually require precursory decisionmaking steps prior to the actual activities in order for the farming cycle to be effective. The previous statement is especially true when farmers have to deal with unfamiliar new kinds of crops [44]. Knowledge such as how to identify crop diseases, the diseases' exhibition locations on crops, and their prevention and cure can save farmers' time and costs in the practice of farming. The following are the subcategories of smartphone applications for farming.

Disease Detection and Diagnosis. Smartphone applications under this subcategory are dedicated to disease detection/diagnosis in farms when utilizing sensors on smartphones. Prasad et al. depicted a mobile vision system which aids in plant disease identification process [13]. The system worked by capturing images of plant leaves being investigated for diseases, then preprocessing those images, and transmitting the processed images to remote laboratories. The image preprocessing step was necessary for saving transmission cost of sending diseased leaf images to plant pathologists in remote laboratories. Leaf images were segmented by a clustering algorithm into three areas: background, nondiseased portion of the leaf, and diseased portion(s) of the leaf. Leaf images were then cropped only to the location of the largest diseased patch on the leaf and transmitted over any available network to lab experts for further disease identification. Closely related to disease detection is suggesting cure and 


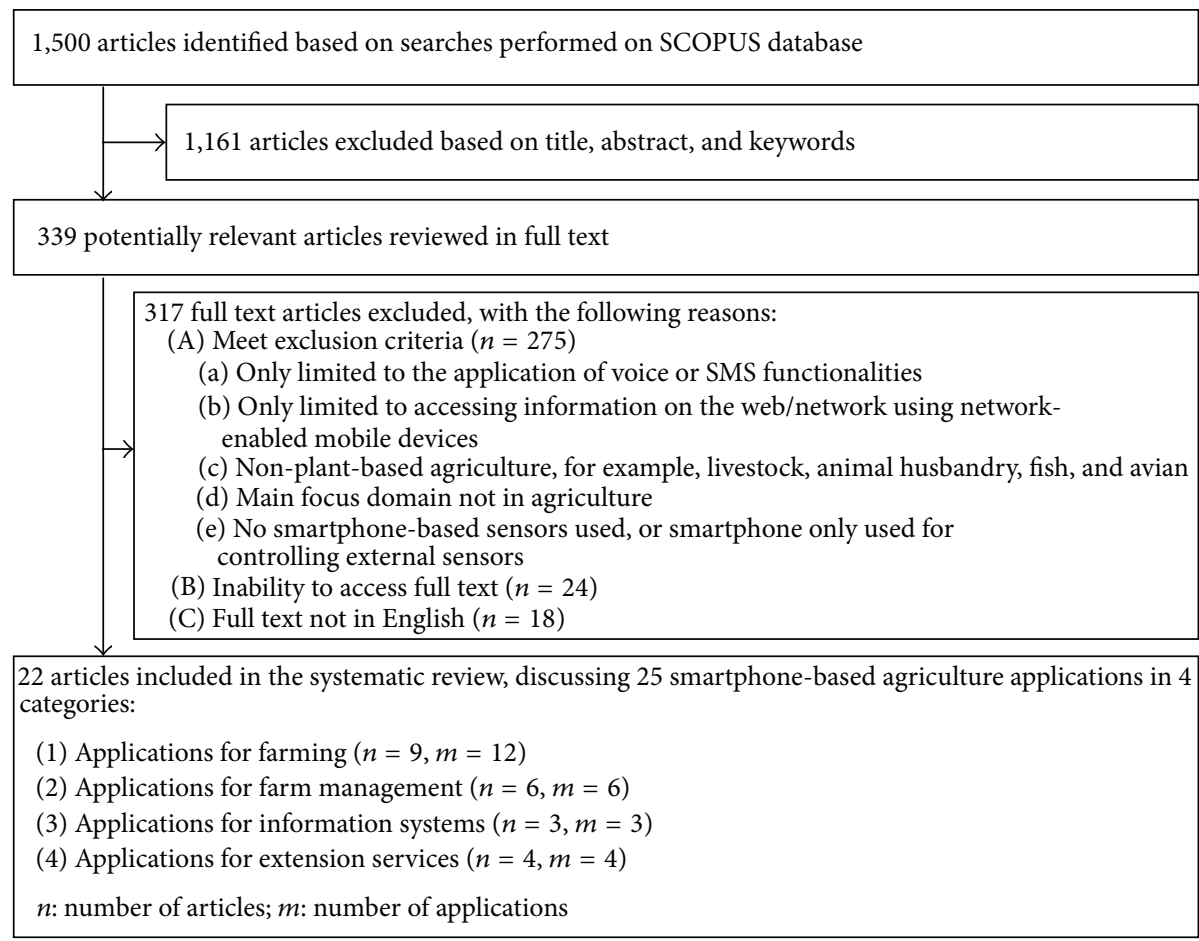

FIGURE 1: Flow diagram of the systematic review of usage of smartphone-based sensors in agriculture.

prevention for the diseases. Wu and Chang proposed a mobile application Magri, which utilized pest/disease information previously self-reported by farmers [25]. Magri's report module generated advice for the cure of pests, as well as pest alerts in nearby areas using GPS.

Fertilizer Calculator. Applying fertilizer is an important farming activity with a potential to greatly affect farm productivity. Decisions on which chemicals to apply and their crop-specific appropriate quantities need to be made by farmers. Sumriddetchkajorn reviewed a few mobile devicebased optical applications for agriculture [16], one of which was a smartphone-based color estimator dedicated for rice leaves' chlorophyll evaluation BaiKhao. The application and its newer released version BaiKhaoNK evaluated the color level of rice leaves and recommended required amounts of nitrogen fertilizer for applying to the rice field $[8,16,17]$.

Soil Study. Soil is another major component in farming which has a great impact on the success of agriculture. Farmers equipped with soil data receive an advantage in farming, including in precision agriculture. There are a number of smartphone applications in the literature that utilized smartphone sensors in studying soil for agricultural purpose. In [14], mobile phones were used as soil color sensors. Soil color information was read from images taken by built-in digital cameras on smartphones and processed using image processing techniques to transform RGB color space into colors in XYZ and HVC spaces. The color conversion was conducted solely on mobile phones and needed no other external software. Another smartphone application,
Soil Indicators for Scottish Soils, SIFSS, was useful for soil study in agriculture [15]. Farmers received soil's detailed information, for example, $\mathrm{pH}$, soil carbon, $\mathrm{N}, \mathrm{P}$, and $\mathrm{K}$, based on their locations in Scotland. SOCiT, also an application aimed at users in Scotland, gave information about soil's carbon content based on users' geographical positions [15]. The location information could be used to look up environmental contexts such as climate and elevation of the area. Then, a mathematical model predicted topsoil organic matter and carbon content based on geographical data along with accompanied soil images.

Water Study. Water quality affects farming and agriculture in nearby regions. A project in Scotland, iDee, developed a smartphone application dedicated to encourage users to submit information of water conditions, that is, water level, water clarity, obstruction in river, algae cover, temperature, nonnative plants in water, and accompanying photographs of the River Dee [15]. Other users in the area could then view those water conditions data.

Crop Water Needs Estimation. Farmers also need to make decisions on the amounts of water their crops need. Crop water requirements depend on various conditions: crop types, season, climate, and growth stages of crops [45]. Crops lose water through transpiration, while nearby soil, water, and canopy lose water through evaporation. This water loss process is collectively called evapotranspiration [45]. Crop water needs are analyzed to supplement water loss in order for crops to grow according to farmers' needs. A smartphone application called PocketLAI helped farmers in 
determining Leaf Area Index (LAI), which is a key factor to calculate crop water requirements [9]. PocketLAI estimated LAI using an indirect method based on sensors available on modern smartphones. Two sensors were main components of this application. Image sensors (cameras) were used to take pictures of leaf canopy to estimate Leaf Area Index. Accelerometers were used to obtain the angle of smartphones as the devices were rotating in order to estimate LAI when the gap fraction was precisely measured at $57.5^{\circ}$. The angle $57.5^{\circ}$ was a directional view angle that had been shown in the agricultural research to allow the estimation of LAI to be free from leaf angle distribution and leaf degree clumping [9]. Once water requirements were determined from Leaf Area Index, farmers could adjust their watering/irrigation tools accordingly. Closely related to LAI calculation is brightness analysis which estimates light brightness intercepted by plants. In $[8,16]$, an application was developed to analyze brightness using cameras on smartphones. The application of brightness analysis was for estimating light radiation on plants. Also, Molina-Martínez et al. presented a mobile application, RaGPS, for devices with Windows Mobile operating system to calculate the extraterrestrial solar radiation and other parameters related to solar position in real-time based on the GPS data [26]. These radiation parameters were useful for estimating crop water needs and validating weather data provided by the agricultural weather stations. Their experiments showed that RaGPS could estimate radiation parameters very similarly to the ones from the weather station in clear-sky days.

Crop Produce Readiness Analysis. An innovative use of smartphone-based sensors is to determine ripeness of fruits. In $[8,16]$, an application was developed utilizing smartphone cameras. Pictures of fruits under white and UV-A light sources were taken to determine ripeness levels for green fruits. Farmers could integrate the system into their farms by separate fruits of different ripeness levels into piles before sending them to markets. With the help of computer vision techniques, this process could be done in bulk rather than farmers manually inspecting each fruit.

Smartphone applications under farming category support farming processes of planting crop by sensing the environment using various sensors. Observations can be in the form of snapped pictures, specific locations in the farm, colors of soil, water, and plant leaves, and light. Main target users of the applications are farmers who are involved with exhaustive farming activities. This type of application aims at improving farm productivity, oftentimes by analyzing agricultural specimens, supporting agricultural decisions, and solving taskspecific problems. Smartphone applications which are under farming category often share a common trait of being highly computational as evident in $[8,9,13,14,16,17]$, compared with smartphone applications in other categories.

4.2. Farm Management Applications. This subsection reviews the literature on applications of smartphone-based sensors for farm management. Research papers in this category consider farming issues from a system perspective. Specifically, smartphone applications in the papers discussed here focus on a whole farm system in contrast to the farming applications discussed in the previous subsection where each farming process, for example, disease identification and prevention, fertilizing, and applying pesticide, was more considered. The main objective of the smartphone applications in this category is to facilitate users to manage overall farm resources and activities more efficiently and effectively in order to achieve their goals, for example, to obtain maximum profit and farming productivity.

Traditionally, farmers might rely solely on paper forms and desktop computers to record, track status, and manage farm resources and farming activities. While they are on the field, they might keep field records, for example, amount of pesticide and fertilizer used, locations and types of weeds and disease found, and yields at each field on paper forms, and then they enter the collected field data to a computer when they are back at the office. Those data are later used for report generation and various analyses (e.g., cost analysis) to improve overall farming productivity. However, this conventional data collecting approach often results in nonintegrated data, making it difficult to extract valuable information from such data. The recent development of smartphone technology has transformed those farm management tasks in many aspects. The mobile nature of the smartphone allows users to access it anywhere anytime. Farmers can easily carry a smartphone with them to the field to record field data and manage farm resources right at the field. Moreover, smartphone-based sensors such as microphone, camera, GPS, accelerometer, and several others can tremendously ease farm journaling and other farm management tasks. For example, farmers can take photos of crops planted and weeds found on the field with GPS coordinates. To label the photos taken, besides typing, some applications use speech recognition technology to aid users, for example, MapIT [19]. GPS technology also enables farmers to track equipment and vehicles at different parts of a farm in real-time. In addition, a common feature of smartphone applications in the farm management category is that most applications are connected to cloud servers where all farm data are integrated, analyzed, and visualized in different formats to support decision making of farm managers/owners in order to improve farming operations. The field data collected via a smartphone are usually synchronized to the cloud servers and are easily accessible from any devices connected to the Internet.

Water Management. Farm management applications assist users to manage various farm resources. Water is one of the crucial resources for crop growing. Better water resource management means better yields and lower farm operating costs. Researchers have proposed and developed smartphone applications for effective water resource management. To design effective water management strategies, water flow data is necessary for daily operations of irrigation channels. In general, to obtain such data, it requires measurement stations, which are expensive, resulting in sparse and low quality data used for water management decision making. Smartphones allow water flow measurement tasks to be done much easier at a lower cost, as it does not require permanent station installation. Lüthi et al. [18] designed and developed 
an Android application for measuring open-channel flow. The application estimates the water level, surface velocity, and discharge rate by analyzing a short video recorded by a smartphone of the water flow between two control points with a known distance. To estimate the water level, the algorithm relied on a separation line of image segments with and without optical flow using a sequence of images. This technique can be done because pixels in the dry parts of the image generally remain unchanged over time, while pixels on the water are subject to constant change. The surface velocity estimation was implemented by a modified method of the standard Particle Image Velocimetry (PIV) method. The preliminary results reveal that the accuracy of the water level, surface velocity, and runoff data obtained via their smartphone application is about $5 \%$ of data obtained from a commercial radar sensor.

HR Management and Farm Activity Journaling. Human resources play an important role in farming productivity, especially for farms in developing countries where agricultural systems rely more heavily on manual labor than machinery. The ability to keep records of farm workers' activities such as weeding, fertilizing, and harvesting in each area of the farm at specific time, schedule farm workers to different jobs, and communicate work plans to farmers is essential for effective farm management. Murakami et al. and Murakami proposed iFarm, a system designed to assist in recording field data and communicating work plans, using smartphones, a cloud server, and web browsers [27, 28]. Farmers in the field use an application on smartphones to record field data and send it to a cloud server. Farmers in the head office can retrieve the information via a web browser. The information can then be used to form a work plan and communicate back to field farmers immediately as a task list on their smartphones. The task list can be location-aware. Although the authors did not state it explicitly, the locationaware task list can be implemented using GPS. Sharma et al. developed a machine learning algorithm application to automatically detect farm workers' activities (e.g., harvesting, bed making, standstill, and walking) based on data collected from various sensors on smartphones carried by farm workers while working in the farm [29]. Based on GPS coordinates, the working pattern of farmers and frequency of visiting certain plot of the farm can be inferred. The usage of different machines, for example, tractor and chopper, can be determined by sound data collected via microphone. The data from 3-axis accelerometer are used to identify various body movements. Such accelerometer data are also tagged with timestamp and the GPS coordinates. The authors investigated the accuracies of multiple classifier algorithms including Naive Bayes, Linear Discriminant Analysis (LDA), and $k$-Nearest Neighbor $(k-\mathrm{NN})$ in detecting various farming activities. In addition, as different placements of the phone result in different sensing data, they also studied the detection of placement of the phone, trouser pocket and upper arm, using the same three classifiers. Their experiment showed that the LDA algorithm outperformed the other two in terms of both activity detection and mobile phone placement identification. These detected farm workers' activity data are useful for monitoring and improving the overall productivity of the farm.

Vehicle Monitoring. Vehicle monitoring and location tracking are another promising feature of recent applications of smartphone-based sensors. Liu and Koc introduced SafeDriving, an iOS application to detect a tractor rollover and report emergency event [30]. Based on a tractor's physical parameters and data from smartphone built-in sensors including accelerometer, gyroscope, and GPS, the application conducts a signal processing and uses a mathematical model to calculate the stability index of the tractor. Once the stability index drops below a certain threshold, a warning appears on the phone screen. When the index is zero indicating a rollover or accident condition, the application sends an email with the date, time, and GPS coordinates of the accident location to emergency contacts.

The applications discussed in this subsection so far mainly target an individual farm manager/farm owner/ farmer at a farm level. However, farm management not only occurs at an individual farm level; there are also available applications that aim to manage collective farmland resources. These are tools to support decision making of top government officials or policy makers to achieve an optimal solution at a macro level, for example, an application to manage farmlands and irrigated areas covering a large region of a country.

Agricultural Land Management. The aggregated geo-data of agricultural areas are useful for monitoring purpose and to support decision making of policy makers. Frommberger et al. developed MapIT, a crowdsourcing tool for collecting geographic information of small objects and agricultural areas [19]. To collect the geo-data, a user takes a photo of the interested area/object and draws an outline of the object on a smartphone screen. Through speech recognition or typing, the user can label the object and then upload it to a server for further analyses. To obtain the original size and shape of the object, their implementation relied on the Douglas-Peucker algorithm to firstly simplify the outline drawn by the user. Then, based on the data from built-in inertial sensors, the distance of the object from the camera, and GPS location, the coordinates in the photo are projected to real-world coordinates, yielding a geo-object of exact original geometry.

4.3. Information System Applications. Information is a key factor in making effective decisions in all industrial sectors including agricultural sector. It is widely recognized that information can help farmers increase agricultural productivity. Up-to-date information about prices as well as market demands helps farmers in choosing the type and amount of crops to grow and where to sell their products, to maximize profits. Prompt crop disease warnings and predictions allow farmers to take actions to minimize damage. Updated farming knowledge educates farmers of new ways to improve their crop yields. While such information may be available, some of the main issues faced by farmers, especially small-scale farmers, are that they are not able to meet the expected yield quality, supply, and demand at the market level due to the lack 
of information visibility at the time of decision making. The fact that farmers are not able to make optimal decisions at different stages of the farming life cycle results in a huge impact on farmers' revenue [46]. Innovative information system for agriculture is an effective solution for this problem. This section discusses three papers on this topic.

Information Localization. In order to provide relevant information to farmers, Jain et al. proposed a hybrid architecture which combines mobile and web technology and uses the location of mobile device to improve the information sent to farmers [31]. The main purpose of this paper is to design a system that can provide the localized information which is very crucial at one location but may be irrelevant to other locations. A database is designed to couple information with mapped location. When a farmer uses their locationenabled mobile device, the mobile application sends the location data to the server and receives localized agricultural information. This helps farmers receive relevant information without having to read through enormous amount of data. While the authors did not specify which sensors to be used, the location data can be retrieved using GPS.

Pest and Disease Information. In contrast to the previous solution which provides a general framework for agricultural information, two papers have discussed solutions for pest and disease management. Rafoss et al. used GPS-enabled mobile phones as a way to fight fire blight in Norway in SMILEX system [32]. As mobile phones connected to the Internet provide a way to quickly receive information and report disease outbreaks, stakeholders (e.g., farmers, policy makers, and field workers) can take appropriate actions to minimize the damage. The application was implemented for mobile devices to be able to display disease outbreak reports on a map and users can also report or edit disease outbreaks. GPS is used to access current location of the mobile phone to retrieve the nearby map and the information. While the case study was conducted on the fire blight survey in Norway, the system is applicable for disseminating most crop disease outbreak information. Similarly, Suen et al. proposed VillageTree which is a mobile application that provides intelligent pest management solutions [20]. VillageTree gathers pest incidence reports from farmers using crowdsourcing approach. Then, the incidence reports which include location data and images taken of crop disease are processed in their server using spatial-temporal analytic and image recognition algorithms. Finally, their system produces warning data and sends alerts and relevant solutions to farmers for them to take preventive measures.

Farmer's information needs can be separated into three stages: know-how, context of planting, and market information [47]. Know-how includes information about crop choices and seed varieties. The knowledge of new crops or seed variety that improve yields is beneficial in improving revenues. Context of planting is information about weather, plant protection, and cultivation practices. The nature of context information is dynamic (e.g., weather changes everyday and pest outbreaks that happen irregularly) and has high impacts on crop yields. Market information, which refers to market prices, market demands, and logistics to sell products, is essential in turning products into revenues. The applications discussed above provide innovative solutions, but only for a subset of the information needs. Reference [31] is a general solution which is applicable to all stages, while $[20,32]$ provide solutions that take crowdsourcing approaches for context stage.

The nature of smartphone applications in this category is a channel for receiving and sending information, which requires less computation and information entry on the smartphone than the applications in previous categories. While it is less obvious how sensors could be used for applications in this category, GPS has been successfully used to enhance the information exchange in the three papers described.

4.4. Extension Service Applications. In many countries around the world, agriculture is the main economic driver, but farmers are still poor and undereducated. Governments provide agricultural extensions as a service that reaches out to farmers to provide assistance, for example, educating farmers of new crops, helping farmers diagnose crop disease, and registering farms to provide subsidy for disaster-affected areas. Conventionally, agricultural extension services were provided by extension workers and experts who visited farms to give farming advice and solutions to specific problems, which required traveling and were resource intensive. Smartphones and information technology have recently made the process easier and more accessible. This section reviews four research papers that facilitate extension services.

Pest and Disease Inspections by Experts. Agricultural extension services include the activities that provide personalized information and solution to rural farmers, one of which is to assist farmers in diagnosis of pest or diseases found in the farmer's plants, so that proper solutions or actions can be taken to alleviate the problems. A few researchers have explored the use of information technology and smartphones to enhance this area of agricultural extensions. Jhunjhunwala et al. implemented a voice-based service through call center to provide personalized solution to 1,200 farmers in Tami Nadu, India [21]. This project was inspired by the success of call center business model in modern industries, which provides personalized solution to customers who face technical problems and seek help through their mobile phones. In call center web technology, customer information is logged in their database and some FAQ pages allow relatively untrained call center operators to assist with the customer's problems. Indian Agricultural Advisory System (AAS) was built by using the call center technology. Farmers can call in to seek help. Farmers can also send pictures taken from their mobile phones to the central server to allow call center personnel and experts to visually inspect their problems. Location data from the mobile device informs call center operators and experts about where the problem occurs. Similarly, Saha et al. explored the design and implementation of an Androidbased prototype, $m$-Sahayak, to allow experts to diagnose and treat plant's (and people's) disease remotely [22]. When farmers face diseased plants, they can take photos or videos of 
the plants and use audio to record their query using their local spoken language. The photos, videos, and audios are sent to the server for agricultural scientist to use the data to provide proper solutions accordingly by call or SMS. In another paper proposed by Jagyasi et al., mKRISHI's phone application allows a farmer to send their query using text, voice, pictures, and videos in a similar manner with $m$-Sahayak [24]. While $m K R I S H I$ 's full system uses external sensors embedded in farms (such as humidity and temperature sensors) to further inform experts of field's context, this part goes beyond the scope of our survey.

As most research found in this area was done in developing countries, the target users' level of literacy was a concern and the use of a lot of textual data and advanced features of smartphones for extension services in research has been limited. Mobile applications that provide remote extension services (similar to $[21,22,24]$ ) are still popularly functioning using voice and SMS (e.g., [21]). However, this group of paper is excluded from this survey because the papers do not utilize smartphone features beyond voice and SMS communication. Yet the remaining results still show that smartphone sensors can enhance extension services. The sensors that have been used in this category are cameras, microphones, and GPS. Camera functionality is used to enhance the communication between farmers and experts, because camera is easy to use and images help communicate problems better than word descriptions and allow experts to quickly and accurately diagnose problems. Microphones allow farmers to record their query as spoken words, which provide an alternative for them when forming queries. GPS adds location as additional information for experts.

Tools for Extension Workers. A different way that smartphones can facilitate extension services is to provide a convenient tool for extension workers. In land plot identification, conventionally, technical staffs go to a farmer's plot with multiple devices (e.g., a GPS, a camera, and an electronic recorder to record data such as the plot code, photograph identification, or date) and management of the devices becomes a tedious task. The staffs have to make sure that the battery of each device is sufficient beforehand and have to switch between devices while working in the field. Mesas-Carrascosa et al. proposed GeoFoto, an Android-based mobile application that assists field workers in land plot identification, which reduces the number of tools the extension worker has to carry into the field [23]. GPS and image data captured from the phone are sent to the central office as field workers visit farms. The data is then analyzed to verify that the correct field is visited. While these tools are not directly used by farmers, they help extension workers in providing extension services more efficiently.

\section{Discussion}

5.1. Summary of Current Usage of Smartphone Sensors. This section discusses how smartphone sensors are used in agricultural research. Table 2 summarizes the papers that use smartphone sensors that were described in the previous section. The most popular sensors in agriculture applications are cameras (used by 16 applications) and GPS (used by 14 applications). Other sensors that are applied include microphone, accelerometer, and gyroscope.

As a large number of smartphone applications in Table 2 utilize cameras and GPS, we examine further into both hardware sensors. GPS are mostly used for location-aware applications, which send/receive essential environmental information for agriculture (such as pests and diseases [20, $25,32]$, weather, soil [15], water [15], and radiation [26]), farm management information [27-29], locations of accident [30], locations of fields [23], and locations of farmers [29], based on users' locations. The aforementioned locationbased information seems to be able to tolerate some levels of location inaccuracy as environmental information or locations of farmers/fields/accidents can be reported in the vicinity of meters. Therefore, GPS on smartphones, even lowpriced ones, represent an ample choice of GPS hardware specifications.

As for image sensors on smartphones, requirements of cameras' technical specifications may be analyzed in two ways. Cameras can be used to take pictures or videos which are then sent and stored as a whole on servers or on the cloud for future reference or further inspection [15, 21-24]. Cameras can also be used to take pictures or videos to be image-processed further $[8,9,13-20]$. The former requires images/videos to be in a sufficiently good enough quality for human inspection. The latter, however, calls for higher quality image sensors for the purpose of image processing. Furthermore, smartphones expected to perform onboard image processing need to meet certain computing power. While some papers report image resolution in which the applications were tested (e.g., 5-megapixel in [9], up to 8megapixel in [13]), some researchers specify processing power requirement [9]. Whether these applications are able to assist farmers, farm managers, and government workers effectively depends on smartphones' specifications.

\subsection{Advantages of Using Smartphone-Based Sensors with} respect to Traditional Methods in Agriculture. This section compares the utilization of smartphone-based sensors in agriculture to that of traditional tools and methods. Table 3 gives a synopsis of advantages of using smartphone-based sensors over traditional methods for each smartphone application. The applications are ordered by categories previously described in Section 4.

\subsection{Challenges of Using Smartphone-Based Sensors in Agricul-} ture. This section explores challenges in the design, development, and implementation of using sensors on smartphone to assist agricultural decisions and management. Challenges that may arise when developing agricultural applications using smartphone-based sensors are divided into challenges due to the nature of the sensors and due to the nature of the applications. First, technical challenges of utilizing smartphones' onboard sensors instead of dedicated sensors are discussed. Then, we examine challenges of building smartphone applications to meet agricultural requirements. 


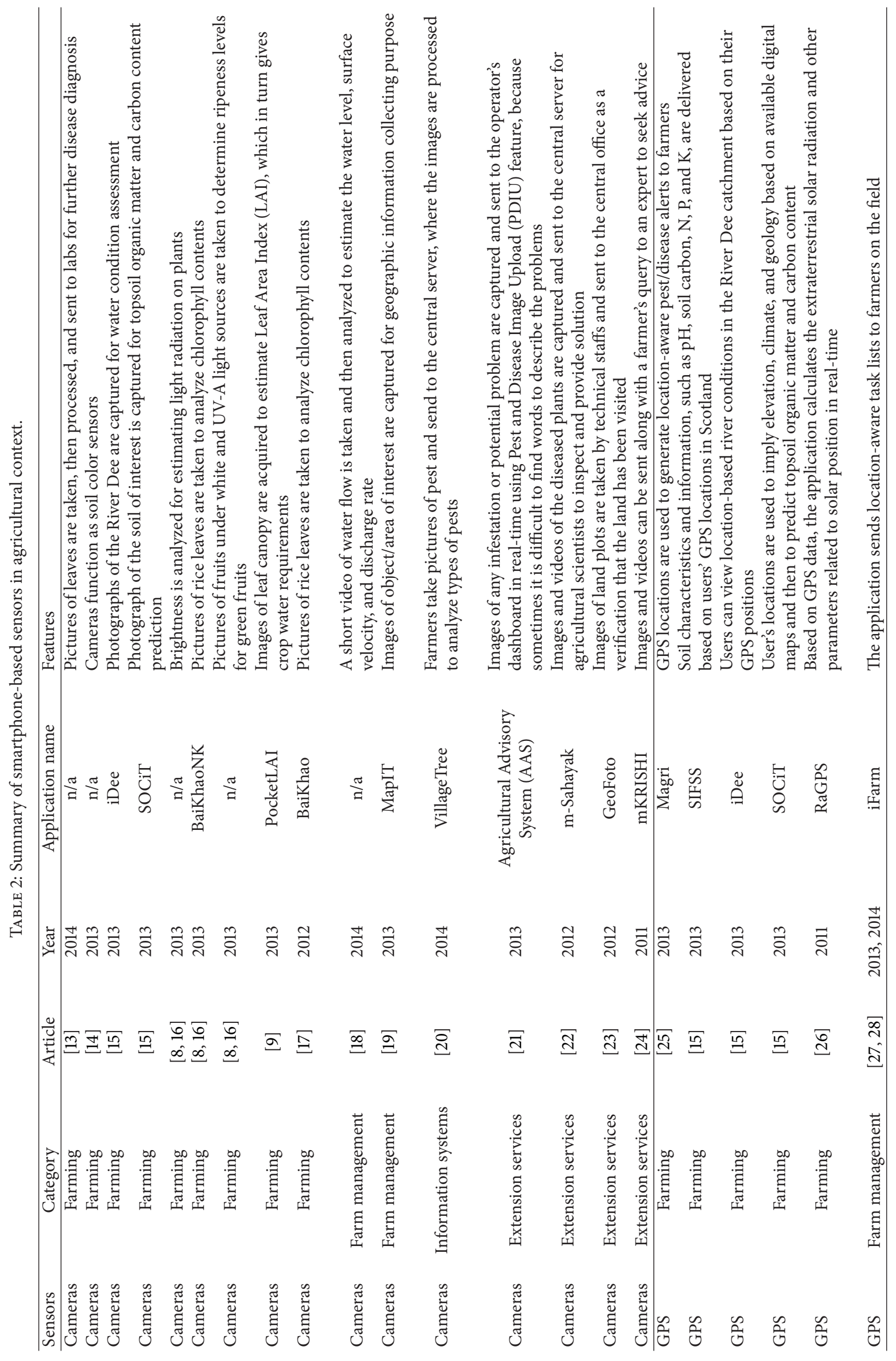




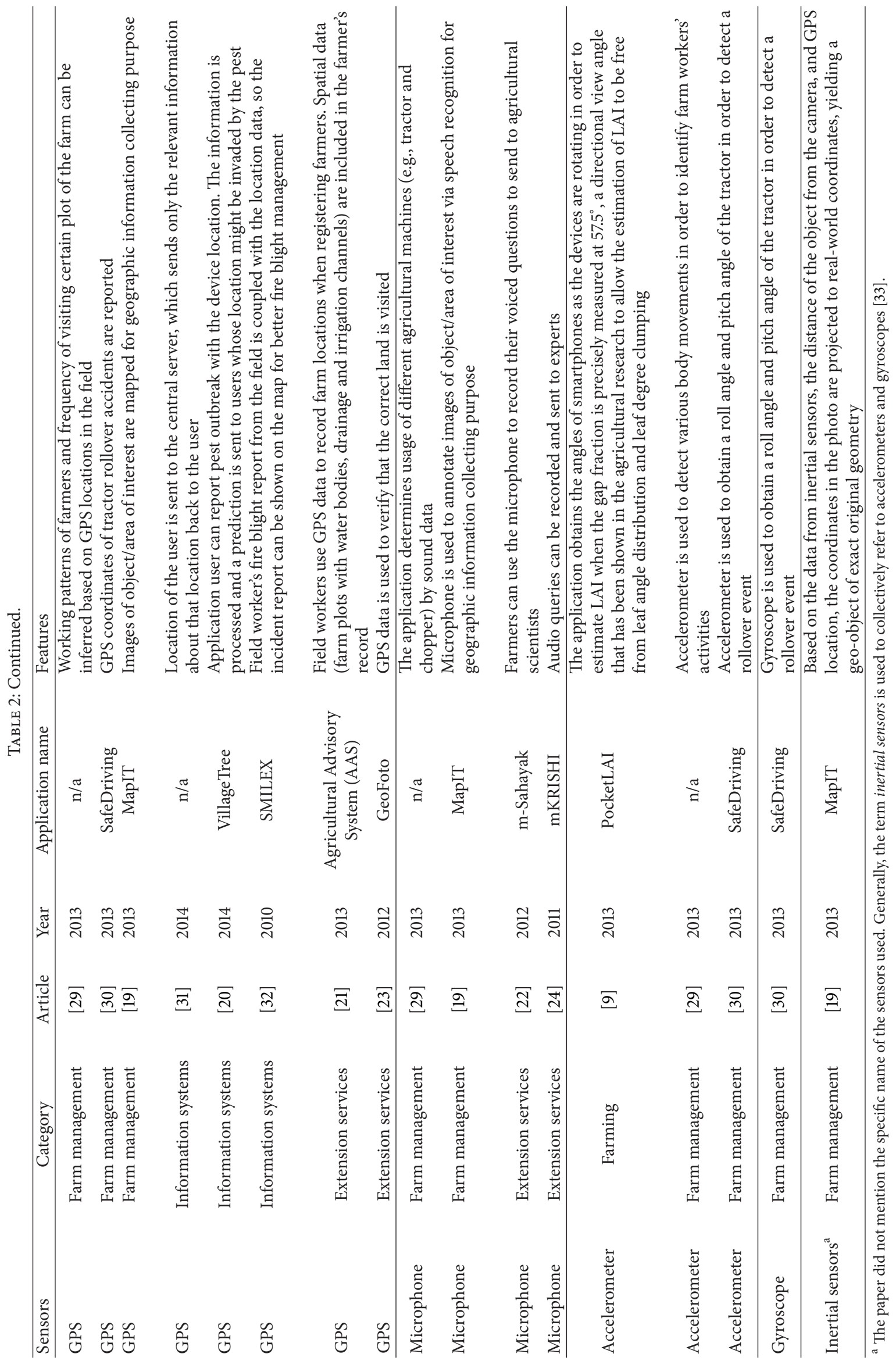




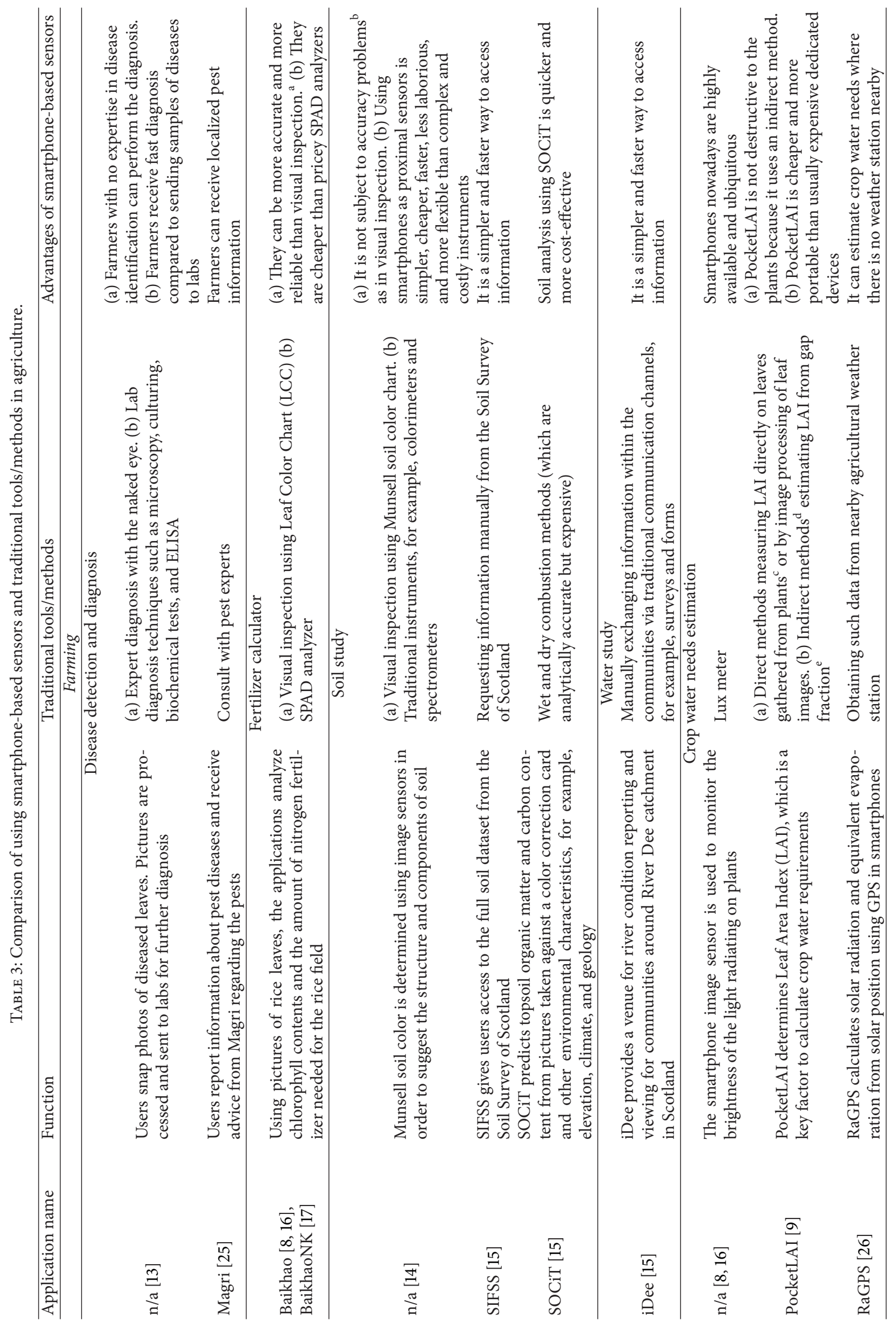




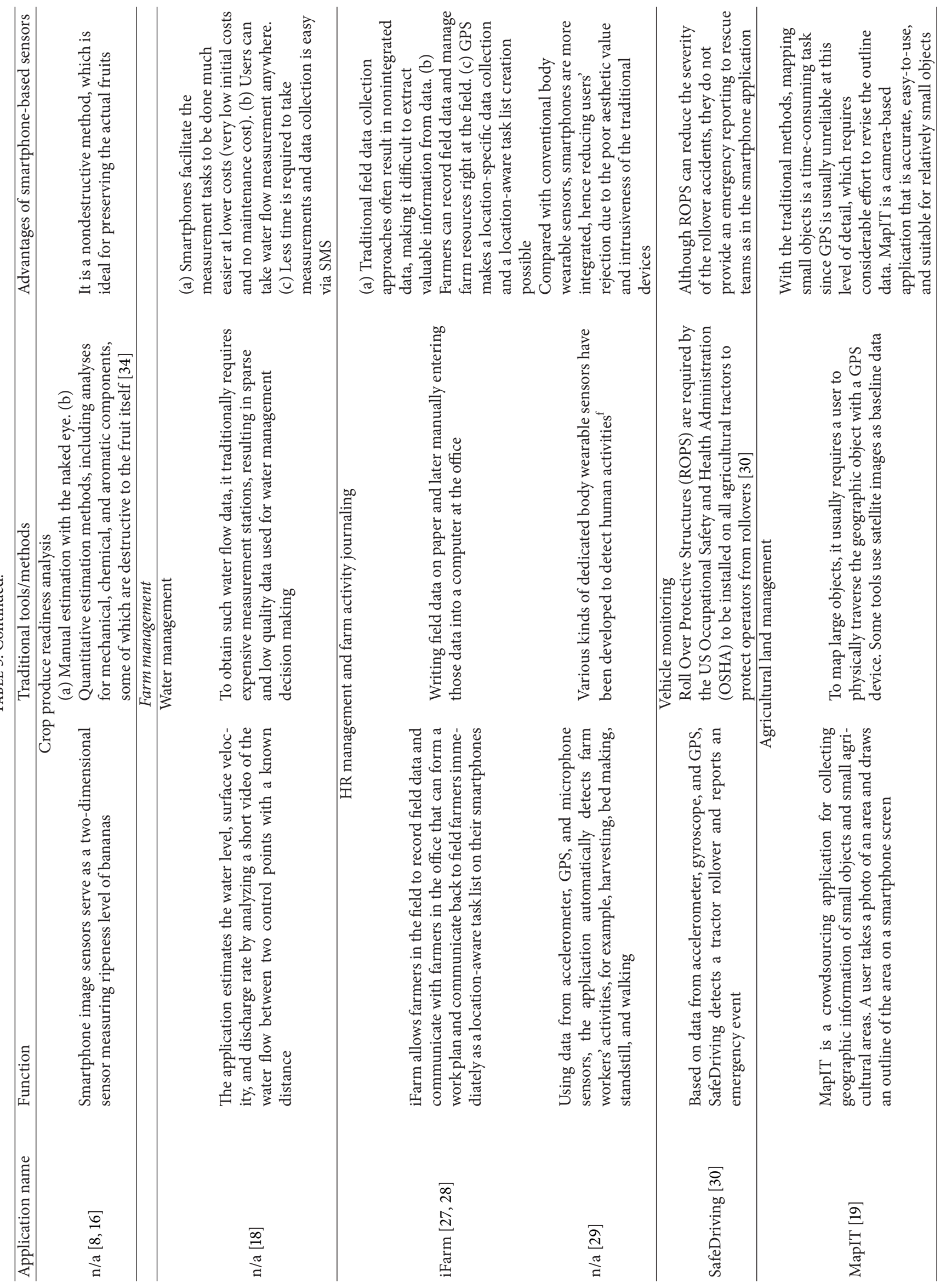




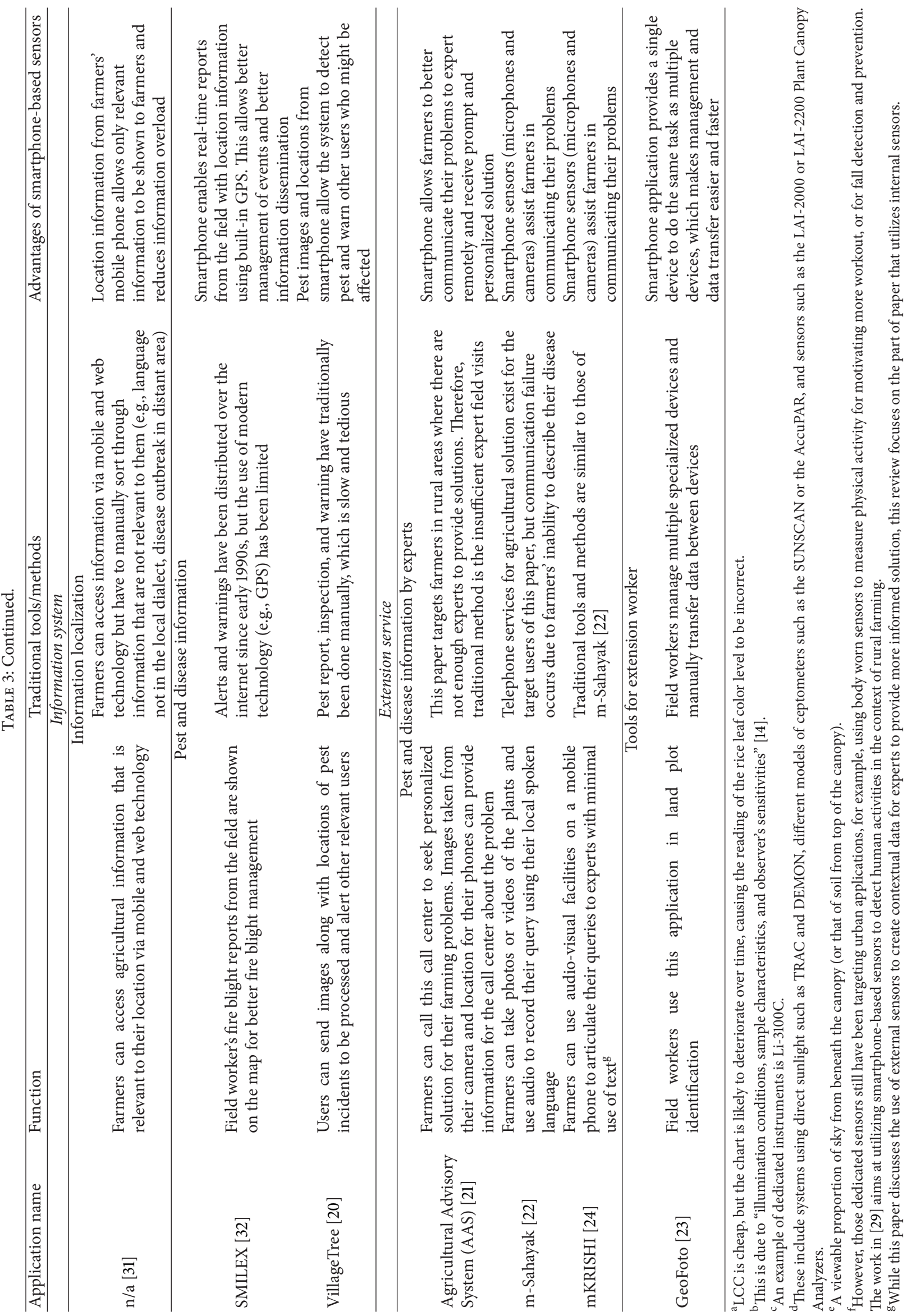


5.3.1. Challenges due to the Nature of the Sensors. Cameras on recent smartphones might be of high specifications, but for some applications they might still be inadequate in quality. Applications that use cameras as sensors for image processing run into trouble when lighting and angles of the objects are not appropriate. Therefore, this poses a challenge for application developers or researchers. In order to use camera sensors as light analyzers, Sumriddetchkajorn describes using an external diffuser on top of the smartphone camera to control the lighting condition [8]. Similarly, Confalonieri et al. utilize accelerometer on smartphones to ensure that the gap fraction is captured when smartphones are at the correct angle ( $57.5^{\circ}$ to be exact).

In this case, smartphone application developers may compare performances between using smartphone sensors and other methods $[8,9]$. Usually the nonsmartphone methods are a more direct way to perform the tasks but require more specific expensive equipment, such as a spectroscopy for soil study [10].

GPS data could be erroneous. While the specific usages that have been reviewed in this paper do not require high accuracy and can tolerate some errors, some of the possible applications could be challenging in the context of smartphone GPS. For example, research suggests that modern dedicated GPS equipment used in precision agriculture can be as accurate as in centimeters [48]. A precise detection of locations allows farmers to be equipped with a decision support system. Coupled with sensing agricultural variables, such as moisture levels, soil organic matter, and nutrition, precise location detection by GPS enables variability within farm management. Researchers and developers need to define the scope of their applications in order to specify required hardware specifications on the sensors.

\subsubsection{Challenges in the Design and Development of Agri-} cultural Applications. Another challenge for mobile developers and researchers in creating practical smartphonebased applications for agriculture is user interface design. In general, the requirements and behaviors of smartphone users are different across farming communities. For example, rural farmers in developing countries might be constrained by low level of literacy and lack of exposure to software interfaces, which probably make the user interface designs for large-scale farms in developed countries inappropriate for them. It is necessary for smartphone application developers to realize this difference and customize the interface design to their target users. Applications which target rural farmers need to have highly intuitive interfaces; using a lot of text as interface might be incomprehensible or difficult for them. Although this fact has been taken into account in the development process of some applications such as in [20], many applications still do not concern this aspect.

Some applications that were reviewed pose some challenges due to the nature of the approaches taken by the application. Saha et al. [22] and Jain et al. [31] took the crowdsourcing approach to assist with the management of pest and disease outbreaks. While this approach allows rapid and distributed data to be inputted to the system, which has advantages over traditional centralized approach, the nature of crowdsourcing approach requires checking of the correctness of the data. The papers did not specify any correctness checking which could pose a problem for the model for pest prediction [22] and the alerts that are sent could be less credible when users make error in reporting.

5.4. Future Research Opportunities. This section synthesizes future research opportunities from the papers that were reviewed. Future research directions are grouped into categories as follows.

Exploration of Unused Sensors. There are many built-in sensors in smartphones which have yet to be explored in the context of agriculture. Physical sensors, for example, barometer and humidity sensor, can be rather easily extended to the agricultural field by performing their original intended functions of environmental sensing. This leaves an open opportunity for researchers and developers to invent useful applications that are enabled or enhanced by these sensors.

Extension of Sensor Usage from Existing Research. Moreover, the sensors that have already been explored can be further explored by replicating previous techniques to smartphones. Computer vision techniques have been studied in the context of agriculture extensively, many of which were proposed as offline computation, for example, weed identification [49] and cotton foreign matter inspection [50]. The current state of server computational power can allow some of these algorithms to be deployed where images are taken using smartphone cameras, sent to server for processing, and the results are returned to senders on their mobile phones.

Additionally, smartphone accelerometers have been proven useful in other fields such as for daily physical activity recognition [51] and for prevention of major health hazards such as fall detection [3]. However, the approaches have been limitedly applied to agricultural field. Similar approaches can be applicable to recognize various farming activities and to provide further assistance in farm journaling. The work in [29] utilized sensing data from accelerometer to detect farming activities including standstill, walking, bed-making, and harvesting, but indeed there are open opportunities to apply similar techniques to detect other farming activities such as sowing, watering, and spraying.

Improvement of Algorithms to Process Sensing Data. In addition to using accelerometer data to detect various types of farming activities, researchers can further improve the algorithms to detect if a farmer performs a certain farming activity in an appropriate manner or not. For example, utilizing data from accelerometer, an algorithm might detect from a farmer's hand movement if he/she is sprinkling fertilizer in a proper way. If not, the application could give a real-time recommendation to the farmer to correct his/her hand movement [29].

Smartphone Battery Usage Reduction. We noticed that most of the papers reviewed here did not consider the battery efficient aspect in the design and development process of their applications. Indeed, one nature of farm work is that 
farmers are usually away from power source, preventing them from recharging their phones once they run out of battery. Therefore, design and development of a battery efficient application is crucial for the practicality of any smartphone application and could be another future direction for research in this area [29].

Appropriate User Interface Design for the Target Users. As mentioned in Section 5.3.2, the wide range of target users for agricultural sector creates a challenge for developing appropriate mobile user interfaces. Intuitive interfaces for respective user groups are important for the success of smartphone applications [20]. Level of literacy and familiarity with gadgets are two of the key factors to consider in smartphone application design.

Scalable and Sustainable Business Model and Longitudinal Study. The majority of research papers covered in this review proposed new ideas and invented new systems to solve problems that arise in agriculture for a certain group of users. While they provide a great solution, most of the solutions are tested in small scale and for a short period of time. It would be useful to extend the proposed solutions spatially and temporally. However, extending a research prototype to a scalable and sustainable solution requires new business models [21]. The success of such models would allow longitudinal studies to be conducted where data is gathered for the same subjects repeatedly over a period of time, which allows us to better understand how effective and sustainable a solution is over a period of time.

Solutions for External Factors Affecting the Effectiveness of Smartphone Applications. Multiple problems have been reported in using smartphone applications, for example, poor mobile network coverage $[23,32]$. While it is expected that network coverage will be continually improved, providing a solution that adapts to network coverage would be beneficial. That is, an application would make use of the Internet when it is available but also allows users to perform their task without the Internet and synchronize with the appropriate database when there is network connection again.

5.5. Limitations. The scope of this systematic survey includes only smartphone applications published in the research literature. While, from our brief searches, there are many interesting applications on the markets both in the App Store and the Play Store, we decided to exclude them from the survey because it is difficult to accurately and thoroughly understand the functionality and how the sensors were used in the applications simply from the descriptions provided by application developers. In contrast, research papers provide detailed description, methodology, and evaluation of the work that was done. While we did our best attempt to review all potentially relevant articles, we could not access 24 papers in full text. Therefore, this survey does not claim to contain the most comprehensive list of invented smartphone applications for agriculture which utilize onboard sensors. However, our systematic survey method, despite yielding a bounded set of results, was further analyzed extensively on application features and sensors.

\section{Conclusions}

This paper presented the state-of-the-art survey of the research literature in how smartphone sensors have been used in agriculture, without the needs for external sensors. The total of 22 articles describing 25 smartphone-based agricultural applications were found to be within our scope. Cameras and GPS were the most widely used sensors. Out of 25 applications, cameras and GPS were used in 16 and 14 applications, respectively. Other sensors (microphones, accelerometer, and gyroscope) were used by a few applications each.

We may draw a few conclusions from our systematic review. First, there is an availability of a number of helpful smartphone applications for target farmers. Most of these applications are easily accessible provided that target users have access to basic smartphones, because most of the reviewed applications devise two sensors, cameras and GPS, and because the two sensors are available in almost all basic smartphones. Second, researchers and smartphone application developers reading our review paper may have an impression of research gap regarding which agricultural applications to develop using smartphone-based sensors, as discussed in Section 5.4. Third, governments and agricultural agencies can respond to how even the most basic sensors on smartphones can be used in agriculture. Since agricultural work is context-based, which is primarily distinguishable by different geographical locations, smartphone applications already available in one scope of context can be developed to fit other crops or countries or regions.

\section{Conflict of Interests}

The authors declare that there is no conflict of interests regarding the publication of this paper.

\section{References}

[1] "2 billion consumers worldwide to get smart(phones) by 2016," 2014, http://www.emarketer.com/Article/2-Billion-Consumers-Worldwide-Smartphones-by-2016/1011694.

[2] A. S. M. Mosa, I. Yoo, and L. Sheets, "A systematic review of healthcare applications for smartphones," BMC Medical Informatics \& Decision Making, vol. 12, no. 1, article 67, 2012.

[3] M. A. Habib, M. S. Mohktar, S. B. Kamaruzzaman, K. S. Lim, T. M. Pin, and F. Ibrahim, "Smartphone-based solutions for fall detection and prevention: challenges and open issues," Sensors, vol. 14, no. 4, pp. 7181-7208, 2014.

[4] W. S. Cheung and K. F. Hew, "A review of research methodologies used in studies on mobile handheld devices in K-12 and higher education settings," Australasian Journal of Educational Technology, vol. 25, no. 2, pp. 153-183, 2009.

[5] M. Milrad and D. Spikol, "Anytime, anywhere learning supported by smart phones: experiences and results from the musis project," Educational Technology and Society, vol. 10, no. 4, pp. 62-70, 2007. 
[6] A. Sasson, "Food security for africa: an urgent global challenge," Agriculture \& Food Security, vol. 1, no. 2, pp. 1-16, 2012.

[7] A. Siuli Roy and S. Bandyopadhyay, "Agro-sense: precision agriculture using sensor-based wireless mesh networks," in Proceedings of the 1st ITU-T Kaleidoscope Academic Conference Innovations in NGN: Future Network and Services (K-INGN '08), pp. 383-388, 2008.

[8] S. Sumriddetchkajorn, "How optics and photonics is simply applied in agriculture?" in International Conference on Photonics Solutions, vol. 8883 of Proceedings of SPIE, June 2013.

[9] R. Confalonieri, M. Foi, R. Casa et al., "Development of an app for estimating leaf area index using a smartphone. Trueness and precision determination and comparison with other indirect methods," Computers and Electronics in Agriculture, vol. 96, pp. 67-74, 2013.

[10] R. Viscarra Rossell and R. Webster, "Discrimination of Australian soil horizons and classes from their visible-near infrared spectra," European Journal of Soil Science, vol. 62, no. 4, pp. 637647, 2011.

[11] Sensors overview-android developers, 2015, http://developer .android.com/guide/topics/sensors/sensors_overview.html.

[12] Apple-iPhone 6-Touch ID, 2015, https://www.apple.com/ iphone-6/touch-id/.

[13] S. Prasad, S. K. Peddoju, and D. Ghosh, "Energy efficient mobile vision system for plant leaf disease identification," in Proceedings of the IEEE Wireless Communications and Networking Conference (WCNC '14), pp. 3314-3319, April 2014.

[14] L. Gómez-Robledo, N. López-Ruiz, M. Melgosa, A. J. Palma, L. F. Capitán-Vallvey, and M. Sánchez-Marañón, "Using the mobile phone as munsell soil-colour sensor: an experiment under controlled illumination conditions," Computers and Electronics in Agriculture, vol. 99, pp. 200-208, 2013.

[15] M. Aitkenhead, D. Donnelly, M. Coull, and H. Black, "Esmart: environmental sensing for monitoring and advising in real-time," IFIP Advances in Information and Communication Technology, vol. 413, pp. 129-142, 2013.

[16] S. Sumriddetchkajorn, "Mobile device-based optical instruments for agriculture," in Sensing Technologies for Biomaterial, Food, and Agriculture 2013, vol. 8881 of Proceedings of SPIE, The International Society for Optical Engineering, May 2013.

[17] Y. Intaravanne and S. Sumriddetchkajorn, "Baikhao (rice leaf) app: a mobile device-based application in analyzing the color level of the rice leaf for nitrogen estimation," in Optoelectronic Imaging and Multimedia Technology II, vol. 8558 of Proceedings of SPIE, The International Society for Optical Engineering, November 2012.

[18] B. Lüthi, T. Philippe, and S. Peña-Haro, "Mobile device app for small open-channel flow measurement," in Proceedings of the 7th International Congress on Environmental Modelling and Software (iEMSs '14), vol. 1, pp. 283-287, June 2014.

[19] L. Frommberger, F. Schmid, and C. Cai, "Micro-mapping with smartphones for monitoring agricultural development," in Proceedings of the 3rd ACM Symposium on Computing for Development (DEV '13), January 2013.

[20] R. C. L. Suen, Y. C. Ng, K. T. T. Chang, B. C. Y. Tan, and M. P.H. Wan, "Interactive experiences designed for agricultural communities," in Proceedings of the 32nd Annual ACM Conference on Human Factors in Computing Systems (CHI EA '14), pp. 551554, May 2014.

[21] A. Jhunjhunwala, J. Umadikar, S. Prashant, and N. Canagarajah, "A new personalized agriculture advisory system reality, potential and technology challenges," in Proceedings of the 19th European Wireless Conference (EW '13), April 2013.

[22] B. Saha, K. Ali, P. Basak, and A. Chaudhuri, "Development of mSahayak-the innovative Android based application for real-time assistance in Indian agriculture and health sectors," in Proceedings of the 6th International Conference on Mobile Ubiquitous Computing, Systems, Services and Technologies (UBICOMM '12), pp. 133-137, September 2012.

[23] F. J. Mesas-Carrascosa, I. L. Castillejo-González, M. S. de la Orden, and A. García-Ferrer, "Real-time mobile phone application to support land policy," Computers and Electronics in Agriculture, vol. 85, pp. 109-111, 2012.

[24] B. G. Jagyasi, A. K. Pande, and R. Jain, "Event based experiential computing in agro-advisory system for rural farmers," in Proceedings of the IEEE 7th International Conference on Wireless and Mobile Computing, Networking and Communications (WiMob '11), pp. 439-444, October 2011.

[25] Y. Wu and K. Chang, "An empirical study of designing simplicity for mobile application interaction," in Proceedings of the 19th Americas Conference on Information Systems (AMCIS '13), vol. 1, pp. 331-338, August 2013.

[26] J. M. Molina-Martínez, M. Jiménez, A. Ruiz-Canales, and D. G. Fernández-Pacheco, "RaGPS: a software application for determining extraterrestrial radiation in mobile devices with GPS," Computers and Electronics in Agriculture, vol. 78, no. 1, pp. 116-121, 2011.

[27] Y. Murakami, S. K. T. Utomo, K. Hosono, T. Umezawa, and N. Osawa, "IFarm: development of cloud-based system of cultivation management for precision agriculture," in Proceedings of the IEEE 2nd Global Conference on Consumer Electronics, pp. 233-234, October 2013.

[28] Y. Murakami, "iFarm: development of web-based system of cultivation and cost management for agriculture," in Proceedings of the 8th International Conference on Complex, Intelligent and Software Intensive Systems (CISIS '14), pp. 624-627, Birmingham, UK, July 2014.

[29] S. Sharma, J. Raval, and B. Jagyasi, "Mobile sensing for agriculture activities detection," in Proceedings of the 3rd IEEE Global Humanitarian Technology Conference (GHTC '13), pp. 337-342, October 2013.

[30] B. Liu and A. B. Koc, "SafeDriving: a mobile application for tractor rollover detection and emergency reporting," Computers and Electronics in Agriculture, vol. 98, pp. 117-120, 2013.

[31] L. Jain, H. Kumar, and R. K. Singla, "Hybrid architecture for localized agricultural information dissemination," in Proceedings of the Recent Advances in Engineering and Computational Sciences (RAECS '14), pp. 1-3, IEEE, Chandigarh, India, March 2014.

[32] T. Rafoss, K. Sælid, A. Sletten, L. F. Gyland, and L. Engravslia, "Open geospatial technology standards and their potential in plant pest risk management-GPS-enabled mobile phones utilising open geospatial technology standards web feature service transactions support the fighting of fire blight in norway," Computers and Electronics in Agriculture, vol. 74, no. 2, pp. 336340, 2010.

[33] X. Niu, Q. Wang, Y. Li, Q. Li, and J. Liu, "Using inertial sensors in smartphones for curriculum experiments of inertial navigation technology," Education Sciences, vol. 5, no. 1, pp. 26-46, 2015.

[34] Y. Intaravanne, S. Sumriddetchkajorn, and J. Nukeaw, "Cell phone-based two-dimensional spectral analysis for banana ripeness estimation," Sensors and Actuators B: Chemical, vol. 168, pp. 390-394, 2012. 
[35] H. Gong, C. Chen, E. Bialostozky, and C. T. Lawson, "A GPS/GIS method for travel mode detection in New York City," Computers, Environment and Urban Systems, vol. 36, no. 2, pp. 131-139, 2012.

[36] A. Anjum and M. U. Ilyas, "Activity recognition using smartphone sensors," in Proceedings of the IEEE 10th Consumer Communications and Networking Conference (CCNC '13), pp. 914-919, IEEE, January 2013.

[37] P. Chaovalit, C. Saiprasert, and T. Pholprasit, "A method for driving event detection using sax with resource usage exploration on smartphone platform," EURASIP Journal on Wireless Communications and Networking, vol. 2014, no. 1, article 135, 2014.

[38] M. Werner, M. Kessel, and C. Marouane, "Indoor positioning using smartphone camera," in Proceedings of the International Conference on Indoor Positioning and Indoor Navigation (IPIN '11), 6, p. 1, September 2011.

[39] S. Kwon, H. Kim, and K. S. Park, "Validation of heart rate extraction using video imaging on a built-in camera system of a smartphone," in Proceedings of the Annual International Conference of the IEEE Engineering in Medicine and Biology Society (EMBC '12), pp. 2174-2177, IEEE, San Diego, Calif, USA, August-September 2012.

[40] F. Lamonaca, Y. Kurylyak, D. Grimaldi, and V. Spagnuolo, "Reliable pulse rate evaluation by smartphone," in Proceedings of the IEEE International Symposium on Medical Measurements and Applications (MeMeA '12), pp. 234-237, May 2012.

[41] D. Moher, A. Liberati, J. Tetzla, and D. G. Altman, "Preferred reporting items for systematic reviews and meta-analyses: the prisma statement," British Medical Journal, vol. 339, 2009.

[42] J. Lee, H.-J. Kim, G.-L. Park, H.-Y. Kwak, and C. Kim, "Intelligent ubiquitous sensor network for agricultural and livestock farms," in Algorithms and Architectures for Parallel Processing, vol. 7017 of Lecture Notes in Computer Science (Including Subseries Lecture Notes in Artificial Intelligence and Lecture Notes in Bioinformatics), pp. 196-204, Springer, 2011.

[43] M. A. K. Jaradat, M. A. Al-Nimr, and M. N. Alhamad, "Smoke modified environment for crop frost protection: a fuzzy logic approach," Computers and Electronics in Agriculture, vol. 64, no. 2, pp. 104-110, 2008.

[44] F. Yang and S. Li, "Development of information support system for the application of new maize variety based on smartphone," IFIP International Federation for Information Processing, vol. 259, pp. 817-824, 2008.

[45] R. Allen, L. Pereira, D. Raes, and M. Smith, "Crop evapotranspiration-guidelines for computing crop water requirements," FAO Irrigation and Drainage Paper 56, 1998.

[46] L. de Silva, J. Goonetillake, G. Wikramanayake, and A. Ginige, "Farmer response towards the initial agriculture information dissemination mobile prototype," in Computational Science and Its Applications-ICCSA 2013, vol. 7971 of Lecture Notes in Computer Science (Including Subseries Lecture Notes in Artificial Intelligence and Lecture Notes in Bioinformatics), pp. 264-278, Springer, 2013.

[47] M. Singhal, K. Verma, and A. Shukla, "Krishi Ville-android based solution for Indian agriculture," in Proceedings of the 5th IEEE International Conference on Advanced Networks and Telecommunication Systems (ANTS '11), December 2011.

[48] C. Koc, "Development of a mobile app for remote monitoring and control of a pull type field sprayer," Journal of Food, Agriculture and Environment, vol. 11, no. 3-4, pp. 2532-2535, 2013.
[49] J. Hemming and T. Rath, "PA—precision agriculture: computervision-based weed identification under field conditions using controlled lighting," Journal of Agricultural Engineering Research, vol. 78, no. 3, pp. 233-243, 2001.

[50] H. Zhang and D. Li, "Applications of computer vision techniques to cotton foreign matter inspection: a review," Computers and Electronics in Agriculture, vol. 109, pp. 59-70, 2014.

[51] A. M. Khan, Y.-K. Lee, S. Y. Lee, and T.-S. Kim, "Human activity recognition via an accelerometer-enabled-smartphone using Kernel Discriminant Analysis," in Proceedings of the 5th International Conference on Future Information Technology (FutureTech '10), pp. 1-6, May 2010. 

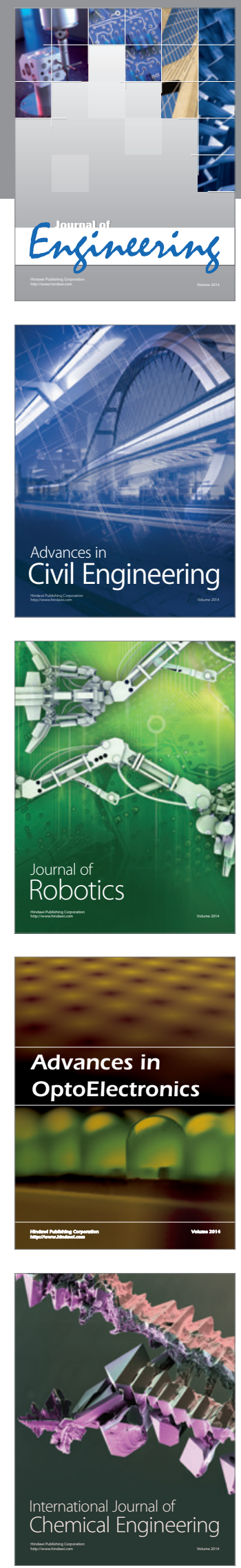

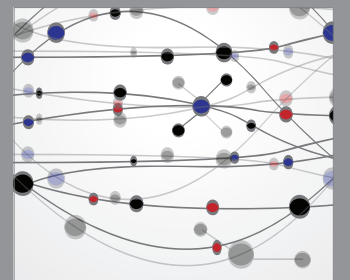

The Scientific World Journal
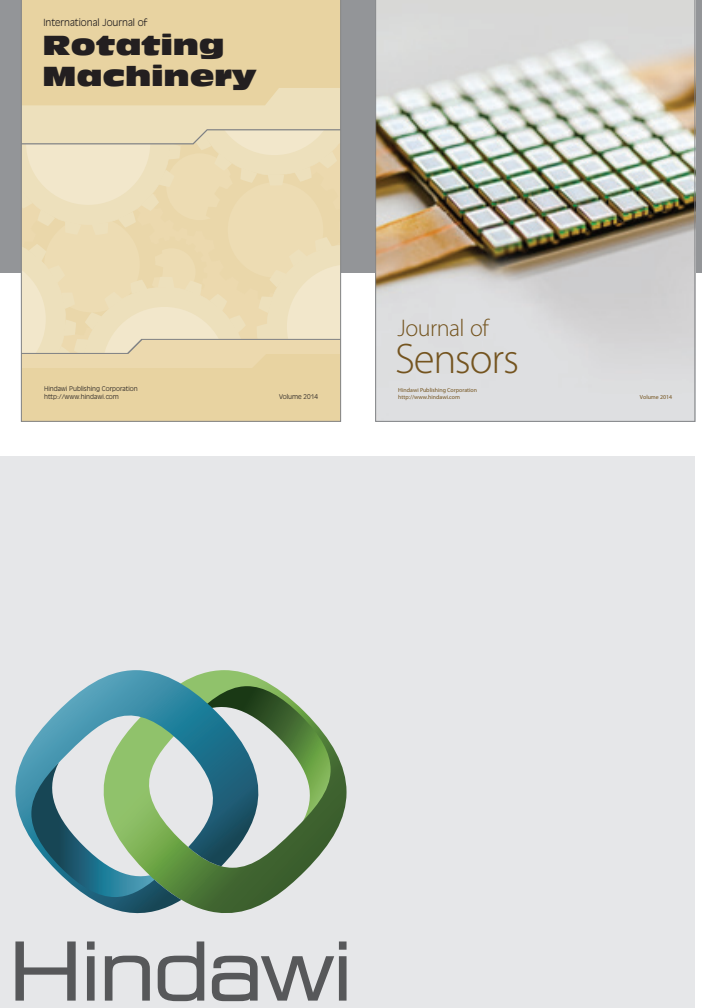

Submit your manuscripts at http://www.hindawi.com
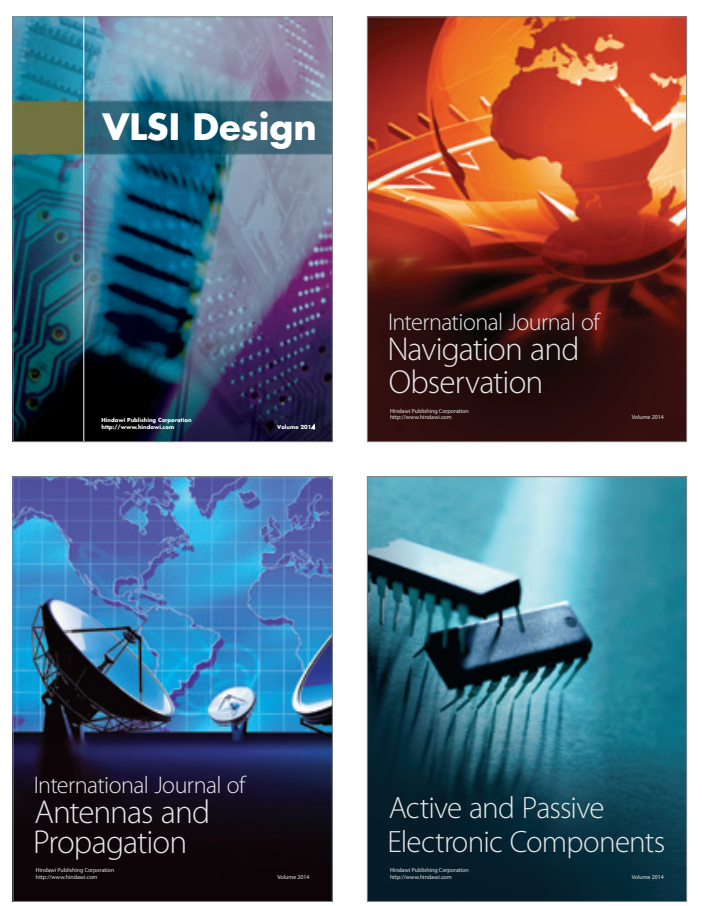
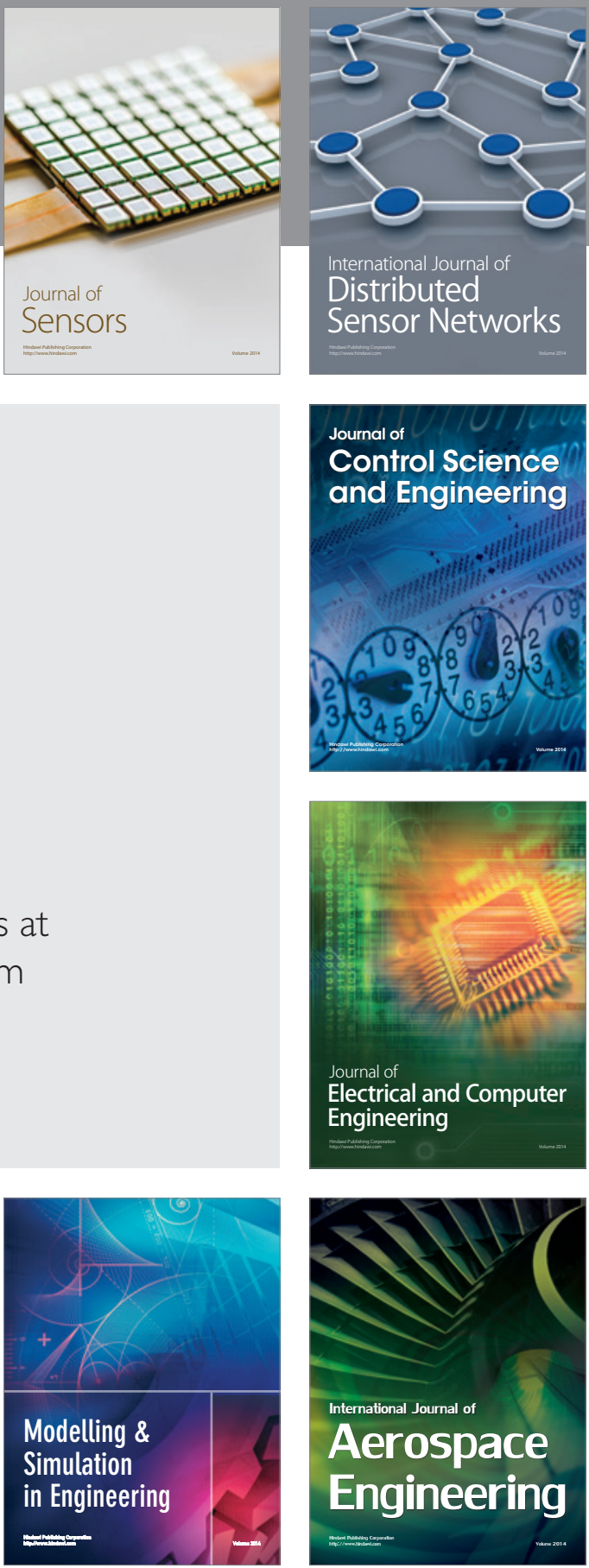

Journal of

Control Science

and Engineering
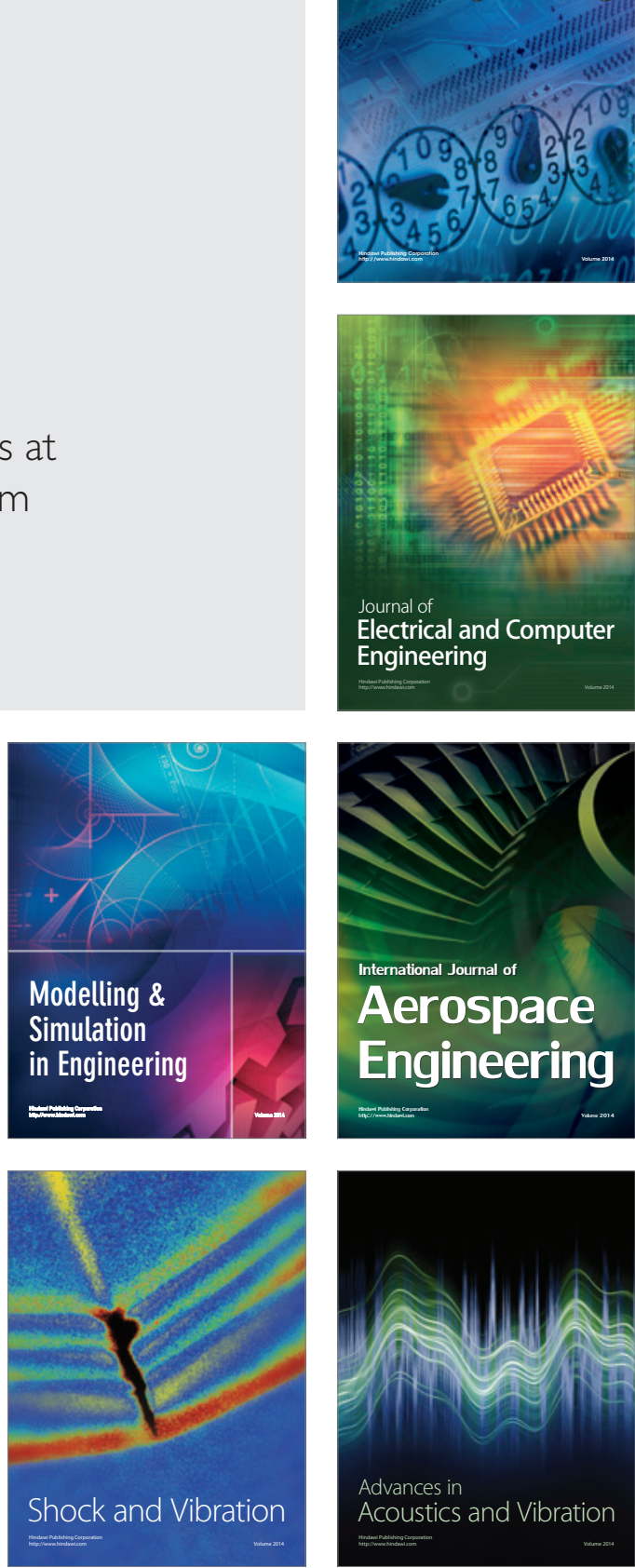